\title{
Decreased microRNA-452 expression and its prognostic significance in human osteosarcoma
}

\author{
Ren-zeng $\mathrm{Li}^{1,2}$ and Li-min Wang ${ }^{1 *}$
}

\begin{abstract}
Background: MicroRNA-452 (miR-452) was previously reported to be dysregulatedin several types of human cancers and involved in tumor progression. The aim of this study was to investigate the clinical significance and prognostic value of miR-452 expression in human osteosarcoma.

Methods: The expression of miR-452 was detected in 95 pairs of osteosarcoma specimens and adjacent noncancerous bone tissues using quantitative RT-PCR (qRT-PCR) assay. Then, the association of miR-452 levels with clinicopathological features and prognosis was analyzed. The roles of miR-452 in regulating osteosarcoma cell proliferation, apoptosis, and invasion were evaluated in vitro.

Results: miR-452 expression was significantly downregulated in osteosarcoma tissues than those in corresponding noncancerous bone tissues $(P<0.001)$. Decreased miR-452 expression was linked to larger tumor size, high tumor grade, advanced clinical stage, distant metastasis, and shorter overall survival. Multivariate Cox regression analysis confirmed that low level of miR-452 expression predieted pook prognosis independently. miR-452 overexpression in MG-63 cells suppressed cell proliferation, promoted cell apoptosis, inhibited cell invasion, and led to decreased BMI1 protein levels.

Conclusions: These findings suggest that miR-452 downregulation may be involved in osteosarcoma formation and progression and that miR-452 would seve as a novelprognostic biomarker for patients with this disease.
\end{abstract}

Keywords: MicroRNA-452, Osteosarcoma, Real-time PCR, Prognosis

\section{Background}

Osteosarcoma is one of the most common primary bone tumors and occurs predominantly in children and young adults [1]. With the development of multiple therapeutic strategies including wide tumor excision, neoadjuvant or adjuvant chemotherapy, and radiotherapy, the 5-year survival of the non-metastatic patients has increased to $65 \%$ [2]. However, osteosarcoma is very aggressive, and approximately $40-50 \%$ of patients will eventually develop metastases, especially pulmonary metastases [3]. The prognosis of these patients is rather poor, and the long-term survival rate is only 10-30\% [4]. Although several genetic alterations have been reported to be linked

\footnotetext{
* Correspondence: manuwanglm@163.com

'Department of Orthopedics, The First Affiliated Hospital of Zhengzhou University, Zhengzhou 450000, Henan Province, People's Republic of China Full list of author information is available at the end of the article
}

with osteosarcoma, the complex molecular mechanisms in osteosarcoma pathogenesis remain largely unclear. Therefore, the identification of novel diagnostic and prognostic biomarkers and potential therapeutic targets is crucial for improving the prognosis of osteosarcoma patients.

MicroRNAs (miRs) are short (about 22 nucleotides in length), highly conserved small non-coding RNA molecules that negatively regulate gene expression by binding to target messenger RNAs (mRNAs) at their 3'-untranslated region, leading to mRNA degradation or translation suppression [5]. It is now clear that miRs play a vital role in diverse biological processes, and deregulation or dysfunction of miRs is involved in a variety of human diseases including cancer [6-8]. Emerging evidence demonstrates that miRs participate in the regulation of cancer cell growth, apoptosis, tumor angiogenesis, epithelial-mesenchymal transition, tumor invasion and metastasis, and 
chemotherapy resistance [9-11]. In osteosarcoma, aberrant expression of several miRs and their functions have been reported. For example, miR-124 showed decreased expression in osteosarcoma tissues, and its downregulation was correlated with advanced clinical stage, positive distant metastasis, and poor response to neoadjuvant chemotherapy [12]. Low miR-217 and miR-646 expression levels were unfavorable prognostic factors for overall survival of osteosarcoma patients [13]. Serum miR-191 and miR-221 may be used as diagnostic biomarkers with the ability to discriminate between patients with osteosarcoma and the healthy cohort $[14,15]$. Restoration of miR-154 in osteosarcoma cells inhibited cell proliferation, colony formation, migration, and invasion, as well as induced cell cycle arrest at the G1 stage [16]. Furthermore, ectopic expression of miR-30a promoted chemotherapy-induced apoptosis and enhanced chemosensitivity in osteosarcoma [17]. Therefore, exploring the roles of miRs in osteosarcoma development and its underlying mechanisms may be helpful for its early diagnosis, accurate assessment, targeted therapy, and prognosis evaluation.

miR-452 is a member of miR-224/miR-452 cluster. Previous studies have proved that miR-224 is involved in tumor formation and progression of several human cancers [18-20]. Recently, aberrant miR-452 expression has been demonstrated in glioma [21], non-small cell lung cancer (NSCLC) [22], bladder cancer [23], prostate cancer [24], urothelial carcinoma [25], and hepatocellular carcinoma [26]. In these malignancies, miR-452 acts as a potential oncogene or a candidate tumor suppressor in different cellular contexts. However, very little is known about the expression and clinical significance of miR452 in human osteosarcoma till now. Therefore, in the current study, we examined miR-452 expression in osteosarcoma specimens and paired adjacent nontumorous tissues and investigated the correlation between miR-452 expression and clinicopathological factors as well as patient's survival. We also explored the role of miR-452 in the regulation of biological behaviors of osteosarcoma cells.

\section{Methods}

\section{Patients and tissue specimens}

Paired fresh osteosarcoma specimens and noncancerous bone tissues were collected from 95 patients at The First Affiliated Hospital of Zhengzhou University (Zhengzhou 450000, Henan Province, People's Republic of China) between January 2007 and December 2010. All the samples were collected before any treatment. The specimens were immediately frozen in liquid nitrogen and stored at $-80{ }^{\circ} \mathrm{C}$ until use. Table 1 shows the details of clinical and pathological characteristics of the patients. The diagnosis was confirmed by two senior pathologists. The clinical stage was classified according to Enneking's staging system [27]. The follow-up data were available and complete for each patient. The overall survival was calculated from the day of primary surgery to death or last follow-up. The Research Ethics Committee of Zhengzhou University approved our study, and all patients provided written informed consent.

\section{Cell culture and transfection}

Human osteosarcoma MG-63 cells were purchased from the Cell Bank of the Chinese Academy of Sciences (Shanghai, China) and grown in Dulbecco's modified Eagle medium (DMEM; Life Technologies, Carlsbad, CA, USA) supplemented with $10 \%$ heat-inactivated fetal bovine serum (FBS) at $37{ }^{\circ} \mathrm{C}$ in a humidified chamber with $5 \%$ carbon dioxide.

miR-452 mimics and negative control (miR-NC) were obtained from GenePharma (China). MG-63 cells were seeded into six well plates and transfected with 50-nM miR-452 minics or miR-NC using Lipofectamine 2000 (Invitrogen, USA) in accordance with the manufacturer protocol.

RNA extraction, reverse transcription, and real-time PCR Total RNA isolation was performed using the miRNeasy Mini Kit (Qiagen, Shanghai, China). Total RNA concentration was assessed by measuring absorbance at $260 \mathrm{~nm}$ using a NanoDrop spectrophotometer (ND-1000, Thermo Scientific, Wilmington, USA). Complementary DNA (cDNA) was synthesized from isolated RNA using TaqMan MicroRNA Reverse Transcription Kit and miRNA specific stem-loop primers (both from Applied Biosystems, Foster City, CA, USA). Real-time PCR was performed with a Taqman MicroRNA Assay Kit (Applied Biosystems, Foster City, CA, USA) on ABI7500 real-time PCR detection system. Quantitative PCR was conducted at $95{ }^{\circ} \mathrm{C}$ for $10 \mathrm{~min}$ followed by 40 cycles of $95^{\circ} \mathrm{C}$ for $15 \mathrm{~s}$ and $60^{\circ} \mathrm{C}$ for $60 \mathrm{~s}$. All reactions were run in triplicate, and miR-452 expression was normalized to U6 small nuclear RNA. The reverse transcription primer for miRNA-452 was $5^{\prime}$-GTCGTATCCAGTGCGTGTCGTG GAGTCGGCAATTGCACTGGATACGACTCAGTT-3' . The PCR primers for miRNA-452 were 5'-GCGCAACT GTTTGCAGAG-3' (forward) and 5'-GTGCAGGGTCCG AGG T-3' (reverse) and those for U6 were $5^{\prime}$-CTCGCT TCGGCAGCACA-3' (forward) and 5'-AACGCTTCACG AATTTGCGT-3' (reverse). The relative amount of miR452 to $\mathrm{U} 6$ was calculated using the equation $2^{-\Delta \mathrm{Ct}}$, where $\Delta \mathrm{CT}=\left(\mathrm{CT}_{\text {miR-452 }}-\mathrm{CT}_{\mathrm{U} 6}\right)$. The fold change of miR-452 in osteosarcoma relative to the matched noncancerous bone tissues was determined by the $2^{-\Delta \Delta \mathrm{Ct}}$ method.

\section{Cell proliferation assay}

Cell viability was evaluated using the MTT method. In brief, MG-63 cells were seeded in a 96-well plate, and 
Table 1 Association of miR-452 expression with clinicopathological factors in osteosarcoma

\begin{tabular}{|c|c|c|c|c|}
\hline \multirow[t]{3}{*}{ Clinicopathological features } & \multirow[t]{3}{*}{ Number of cases } & \multicolumn{2}{|c|}{ miR-452 expression } & \multirow[t]{3}{*}{$P$} \\
\hline & & High & Low & \\
\hline & & $n(\%)$ & $n(\%)$ & \\
\hline \multicolumn{5}{|l|}{ Age } \\
\hline$<20$ years & 70 & $33(47.1 \%)$ & $37(52.9 \%)$ & \\
\hline$\geq 20$ years & 25 & 15 (60.0\%) & $10(40.0 \%)$ & \\
\hline \multicolumn{5}{|l|}{ Gender } \\
\hline Male & 68 & 35 (51.5\%) & $33(48.5$ & 823 \\
\hline Female & 27 & $13(48.1 \%)$ & & \\
\hline \multicolumn{5}{|l|}{ Tumor size } \\
\hline$>8 \mathrm{~cm}$ & 39 & 14 (35.9\%) & & 0.012 \\
\hline$\leq 8 \mathrm{~cm}$ & 56 & 34 (60.7 \%) & & \\
\hline \multicolumn{5}{|l|}{ Anatomic location } \\
\hline Tibia/femur & 66 & $31(47.0 \%)$ & & 0.374 \\
\hline Elsewhere & 29 & $17(58.6 \%)$ & $12(41.4 \%)$ & \\
\hline \multicolumn{5}{|l|}{ Tumor grade } \\
\hline Low & 31 & $22(71.0 \%)$ & $9(29.0 \%)$ & 0.008 \\
\hline High & 64 & $26(40.6$ & $38(59.4 \%)$ & \\
\hline \multicolumn{5}{|l|}{ Histological type } \\
\hline Osteoblastic & 33 & 10 & $14(42.4 \%)$ & 0.830 \\
\hline Fibroblastic & 21 & $10(47.6 \%)$ & $11(52.4 \%)$ & \\
\hline Chondroblastic & 14 & $6(42.9 \%)$ & $8(57.1 \%)$ & \\
\hline Telangiectatic & 15 & $8(53.3 \%)$ & $7(46.7 \%)$ & \\
\hline Others & 12 & $5(41.7 \%)$ & 7 (58.3 \%) & \\
\hline \multicolumn{5}{|l|}{ Enneking stage } \\
\hline I & & $20(83.3 \%)$ & $4(16.7 \%)$ & $<0.001$ \\
\hline$\|$ & & $23(47.9 \%)$ & 25 (52.1\%) & \\
\hline III & & $5(21.7 \%)$ & 18 (78.3 \%) & \\
\hline \multicolumn{5}{|l|}{ Distant metastasis } \\
\hline Absent & & 43 (59.7\%) & $29(40.3 \%)$ & 0.001 \\
\hline Present & 23 & $5(21.7 \%)$ & 18 (78.3 \%) & \\
\hline
\end{tabular}

$20 \mu \mathrm{l}$ MTT solation (Sigma, USA) was added to the culture medium every $24 \mathrm{~h}$, after transfection with miR-452 mimics or miR-NC. After $4 \mathrm{~h}$, the medium was removed, and $150 \mu \mathrm{L}$ DMSO was added to dissolve the formazan. Optical density was measured at $490 \mathrm{~nm}$, using a plate reader (Molecular Devices, Sunnyvale, CA, USA).

\section{Flow cytometry analysis}

After transfection with miR-452 mimics or miR-NC, the MG-63 cells were washed and resuspended in phosphate-buffered saline and then doubly stained using the Annexin V-FITC/Propidium Iodide kit (BD Biosciences, USA). After incubation in the dark for 15 min, cells were analyzed with a FACScan flow cytometer (BD Biosciences, USA).

\section{Cell invasion assay}

Cell invasiveness was determined by using Transwell insert chambers ( $8 \mu \mathrm{m}$ pore size; Corning, USA). After miRNA transfection, the MG-63 cells were collected and resuspended in serum-free medium at a concentration of $5 \times 10^{4}$ cells $/ \mathrm{ml}$ and $200 \mu \mathrm{l}$ cell suspensions were then added into the upper chamber. The bottom chamber was filled with $500 \mu \mathrm{l}$ culture medium containing $10 \%$ FBS. After the incubation for $24 \mathrm{~h}$, the non-invaded cells were removed by a cotton swab, and cells on the lower surface of the membrane were stained with crystal violet and counted.

\section{Western blot}

Cells were lysed in RIPA buffer with protease inhibitors and phosphatase inhibitors. The protein extracts were 

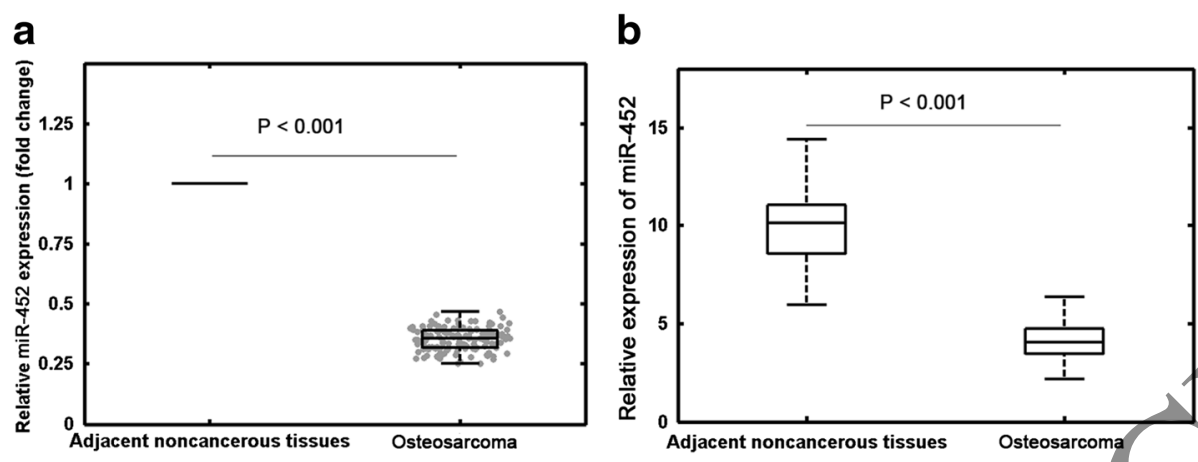

Fig. 1 The relative expression levels of miR-452 in osteosarcoma specimens and matched adjacent noncancerous bone tissues. a the fold change of miR-452 in osteosarcoma relative to the matched adjacent noncancerous bone tissues. b miR-452 expression was significantly lower in osteosarcoma specimens than in the corresponding adjacent noncancerous bone tissues. miR-452 levels were calculated by the $2^{-\Delta C t}$ method and normalized to U6 small nuclear RNA

loaded onto a $10 \%$ sodium SDS-PAGE gel and transferred to a PVDF membrane. The blots were probed with primary antibodies (anti-BMI1, 1:1000, Abcam, Cambridge, UK) followed by the HRP-conjugated secondary antibody. Following three Tris-buffered saline containing $0.1 \%$ Tween-20 (TBST) washes, the membranes were developed using ECL Plus (Millipore, MA, USA) and exposed to X-ray film. GAPDH served as the loading control.

\section{Statistics}

All statistical analyses were performed using the SPSS for Windows statistical software, version 16.0 (SPSS, Chicago, IL, USA). Data are presented as the mean \pm standard deviation (SD). The differences between two groups were analyzed using the Student's $t$ test. The relationship between miR-452 levels and clinicopathologic parameters was analyzed by chi-square test. Survival curves were constructed with the Kaplan-Meier method and compared by log-rank tests. The multivariate analyses were evaluated with Cox proportional hazards models. $P<0.05$ was considered statistically significant.

\section{Results}

Decreased miR-452 expression in osteosarcoma samples miR-452 expression was detected by using quantitative real-time PCR ( $\mathrm{QRT}$-PCR) and normalized to U6. Figure 1a shows decreased miR-452 expression in osteosarcoma compared to matched adjacent noncancerous bone tissues. Figure $1 \mathrm{~b}$ shows that the relative level of miR-452 in osteosarcoma specimens was significantly lower than that in corresponding noncancerous bone tissues (mean $\pm \mathrm{SD}$, $4.03 \pm 0.96$ vs. $10.07 \pm 1.98, P<0.001)$.

\section{Association between miR-452 expression and clinicopathological factors}

The median miR-452 expression level was used as a cutoff value to divide all 95 patients into two groups: high
miR-452 expression group $(n=48)$ and low miR-452 expression group $(n=47)$. As shown in Table 1 , we found that low miR-452 expression was significantly associated with larger tumor size $(P=0.012)$, high tumor grade $(P=0.008)$ advanced Enneking stage $(P<0.001)$, and distant metastasis $(P=0.001)$. However, there were no significance between miR-452 expression and other clinicopathological factors, such as age, gender, anatomie location, and histological type.

\section{Prognostic value of miR-452 in osteosarcoma}

Then, we evaluated the prognostic significance of miR-452 expression in patients with osteosarcoma. As shown in Fig. 2, patients in high miR-452 expression group had longer overall survival than those in low miR-452 expression group $(P<0.001)$. Univariate Cox regression analysis demonstrated that larger tumor size $(P=0.026)$, high tumor grade $(P=0.015)$, positive distant metastasis $(P=0.002)$, and advanced Enneking stage $(P<0.001)$ were also significantly associated with shorter overall survival (Table 2 ).

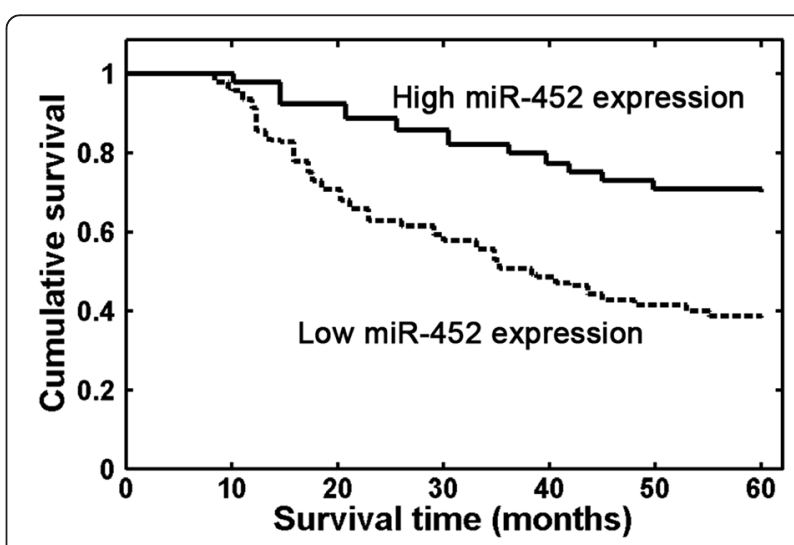

Fig. 2 Osteosarcoma patients with low miR-452 expression had a significantly shorter overall survival than those with high miR-452 expression $(P<0.001$, log-rank test $)$ 
Table 2 Cox regression analysis of factors associated with overall survival in 95 osteosarcoma patients

\begin{tabular}{llllll}
\hline Variable & \multicolumn{2}{l}{ Univariate analysis } & & \multicolumn{2}{c}{ Multivariate analysis } \\
\cline { 2 - 3 } & HR & $P$ value & & HR & $P$ value \\
\hline Age & 1.638 & 0.223 & & - & - \\
Gender & 1.126 & 0.772 & & - \\
Anatomic location & 1.695 & 0.178 & & - \\
Tumor grade & 3.572 & 0.015 & & 3.013 & 0.022 \\
Tumor size & 3.108 & 0.026 & & 1.165 & 0.082 \\
Clinical stage & 5.979 & $<0.001$ & & 5.458 & 0.001 \\
Distant metastasis & 4.392 & 0.002 & & 4.985 & 0.003 \\
miR-452 & 5.756 & $<0.001$ & & 3.263 & 0.018 \\
\hline
\end{tabular}

Multivariate analyses using the Cox proportional hazards regression model revealed that miR-452 expression (relative risk (RR) 3.263; $P=0.018$ ), tumor grade (RR 3.013; $P=0.022$ ), distant metastasis (RR 4.985; $P=0.003$ ), and Enneking grade (RR 5.458; $P=0.001$ ) were independent prognostic factors for overall survival of osteosarcoma.

The effects of miR-452 on the biological behavior of MG-63 cells

Further, we assessed the biological rote of miR-452 in MG-63 cells. Transfection with miR-452 mimics resulted in increased miR-452 level in MG-63 cells $)(P<0.001$, Fig. 3a). The MTT assay showed that miR-452 overexpression obviously reduced MG-63 cell proliferation

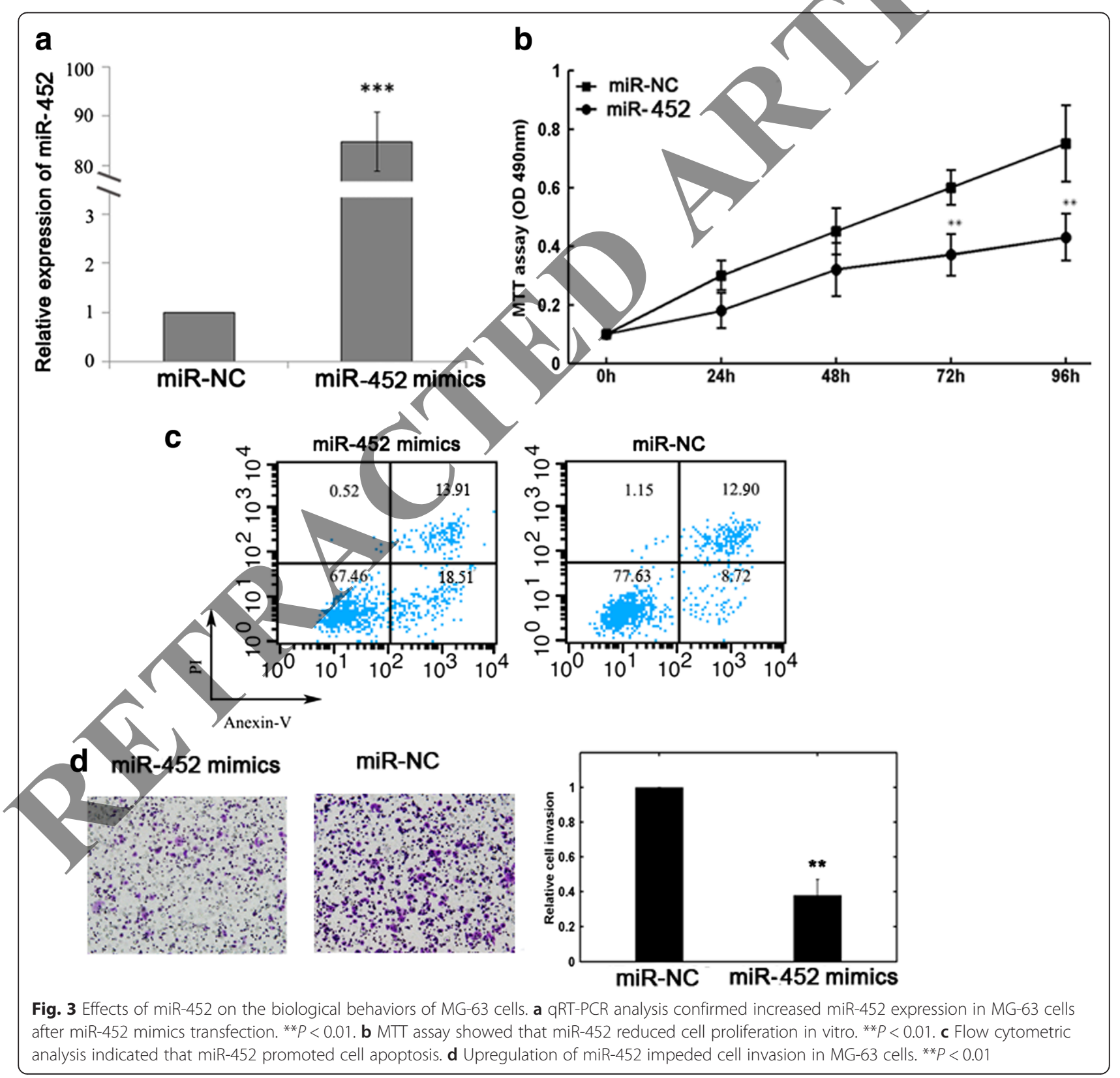


(Fig. 3b). Flow cytometry confirmed promoted apoptosis in miR-452-overexpression MG-63 cells (Fig. 3c). Transwell invasion assay showed that miR-452 mimic transfection impeded MG-63 cell invasion ability (Fig. 3d).

\section{miR-452 could downregulate BMI1 expression in MG-63} cells

At last, we detected the changes in BMI1 protein levels after miR-452 mimic transfection by western blot. The results showed that miR-452 overexpression in MG-63 cells led to the downregulation of BMI1 protein levels (Fig. 4).

\section{Discussion}

Up to now, the exact mechanisms underlying osteosarcoma are not fully understood. Identification of genetic alterations would be important for the screening, diagnosis, and treatment of osteosarcoma. Accumulating evidence has suggested the important roles of miRs in tumor formation and progression. In the present study, we revealed that the expression of miR-452 was significantly reduced in osteosarcoma tissues, and reduced miR-452 expression was significantly associated with larger tumor size, high tumor grade, advanced clinical stage, and distant metastasis. Patients with low level of miR-452 showed shorter overall survival than those with

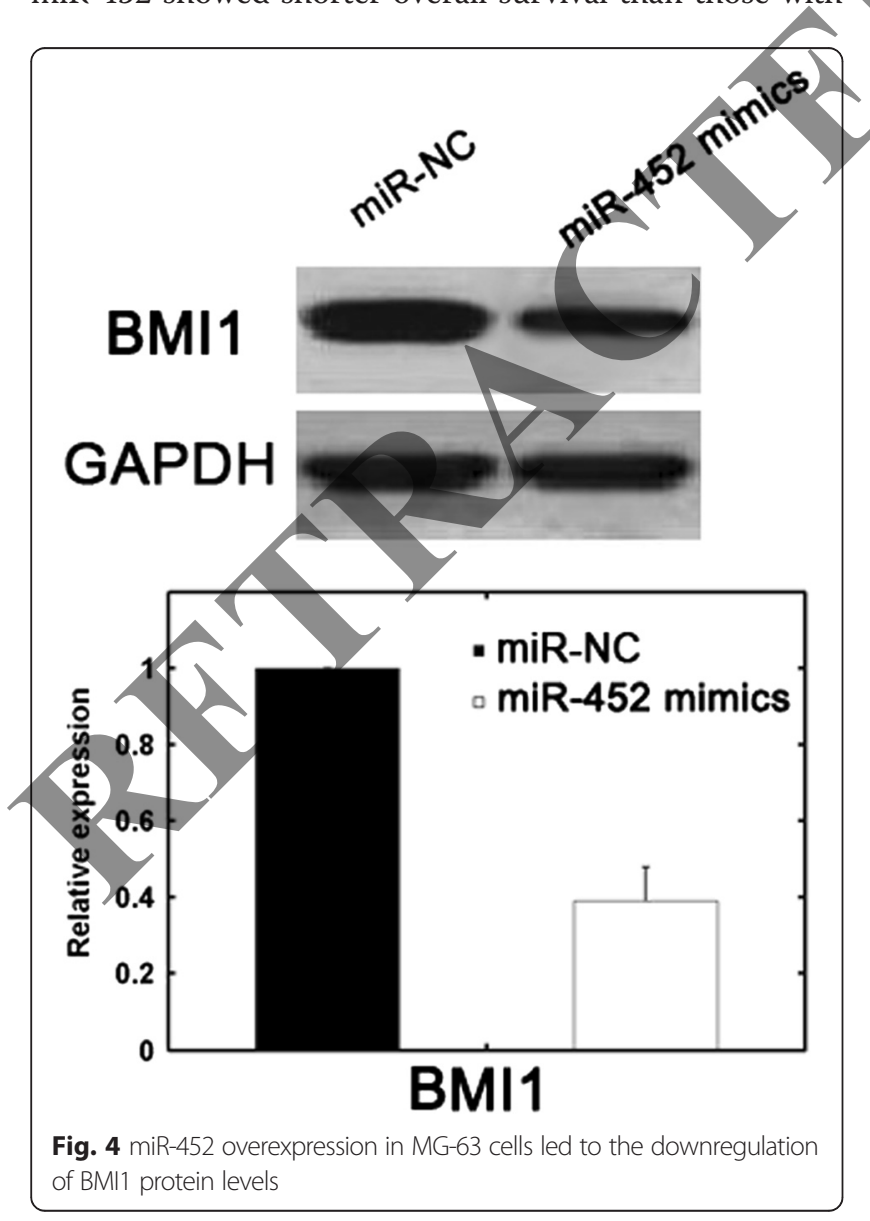

high miR-452 level. miR-452 overexpression in MG-63 cells suppressed cell proliferation, promoted cell apoptosis, and inhibited cell invasion in vitro. Thus, loss of miR-452 expression might be involved in osteosarcoma development and serve as a novel biomarker for poor prognosis.

Previous research has demonstrated the tumorsuppressive function of miR-452 in several human malignancies. For example, Kristensen et al. reported that miR-452 inhibited proliferation, migration, and invasion of PC3 and DU145 prostate cancer cells $\{24\}$. He et al/showed miR-452 downregulation in NSCLC tissues and its association with positive tumor metastasis and advanced TNM stage [22]. Zhang et al. reveated that upregulated miR-452suppressed NSCLC cell epithelial-mesenchymal transition and further disrupted migration and invasion [28]. In human gliomas, decreased miR-452 expression was correlated with shorter patient survival time [21]. Ectopic expression of miR-452 reduced tumorigenicity in a nude mouse xenograft model. Furthermore, overexpression of miR452 in MCF-7 breast cancer cells could significantly enhance cell apoptotic and increase chemosensitivity to Adriamycin [29].

In contrast to the antitumor properties mentioned above, miR-452 may act as a potential oncogene in bladder cancer and hepatocellular carcinoma [23, 25, 26]. Overexpression of miR-452 in HepG2 and QGY-7703 hepatocellular carcinoma cells dramatically accelerated proliferation, induced cell cycle from G1 to S transition, blocked apoptosis, and promoted cell migration and invasion in vitro [26]. Increased miR-452 expression in bladder urothelial carcinomas was associated with high incidence of lymph nodes metastasis and poor prognosis [25]. Thus, the function of miR-452 may be complex in different cancer types, and the role of miR-452 should be tumor specific and possibly dependent on the nature of its targets.

Undoubtedly, miRs exert important functions in carcinogenesis by regulation of target gene expression [30]. In human cancers, some highly expressed miRs could function as oncogenes by repressing tumor suppressor genes, whereas low-expressed miRs could function as tumor suppressors by negatively regulating oncogenes [31]. Previous studies have reported several downstream genes of miR-452, including BMI1 [22], CDKN1B [26], IGF-1R [29], and KRAS [32]. BMI1 has been identified as an oncogene in several cancers [33-36]. Wu et al. revealed that overexpression of BMI1 could promote osteosarcoma cell growth and induce resistance to cisplatin [37]. He et al. identified BMI1 as a direct target of miR-452 in NSCLC [22]. Our study also observed decreased BMI1 protein levels in MG-63 cells after miR-452 overexpression. However, there is no "one-to-one" connection between miRs and target mRNAs. An average miR can have more 
than 100 targets [38]. Conversely, several miRs can converge on a single transcript target [39]. Therefore, the potential regulatory circuitry afforded by miR-452 is enormous, and the accurate mechanisms on how miR-452 influences osteosarcoma progression need further clarification.

\section{Conclusions}

In summary, our research showed miR-452 downregulation in osteosarcoma and its correlation with aggressive clinicopathological features. Decreased miR-452 expression might be an independent biomarker for poor prognosis. Large-scale prospective studies are needed to confirm our conclusion and clarify the mechanisms.

\section{Competing interests}

The authors declare that they have no competing interests.

\section{Authors' contributions}

LW conceived and designed the experiments. RL performed the experiments. $\mathrm{RL}$ analyzed the data. LW contributed reagents/materials/analysis tools. $\mathrm{RL}$ wrote the paper. Both authors read and approved the final manuscript.

\section{Acknowledgements}

None.

\section{Author details}

${ }^{1}$ Department of Orthopedics, The First Affiliated Hospital of Zhengzhou University, Zhengzhou 450000, Henan Province, People's Republic of Ch 2Department of Orthopedics, People No.3 Hospital of Anyang, Anyang 455000, Henan Province, People's Republic of China.

Received: 4 February 2016 Accepted: 10 May 2016 Published online: 18 May 2016

\section{References}

1. Geller DS, Gorlick R. Osteosarcoma: a review of diagnosis, mahagement, and treatment strategies. Clin Adv Hematol Oncol. 2010;8(10):705-18.

2. Bielack SS, Kempf-Bielack B, Delling G, Exner GU, Flege S, Helmke K, Kotz R, Salzer-Kuntschik M, Werner M, Winkelmann W, et al.Prognostic factors in high-grade osteosarcoma of the extremities or trynk: an analysis of 1,702 patients treated on neoadjurant cooperative osteosarcoma study group protocols. J Clin Oncol. 2002:20(3):776-90.

3. Eppert K, Wunder JS, Aneliunas V, Kandel R, Andrulis IL. von Willebrand factor expression in osteosarcoma metastasis. Mod Pathol. 2005;18(3):388-97.

4. Meyers PA. Muramyl tripeptide (mifamurtide) for the treatment of osteosarcoma. Expert Rev Anticancer Ther. 2009:9(8):1035-49.

5. Bartel DP. MicroRNAs: genomics, biogenesis, mechanism, and function. Cell. 2004:116(2):281-97.

6. Xu Ł, Fengji L, Changning L, Liangcai Z, Yinghui L, Yu L, Shanguang C, dianghui $X$. Comparison of the prognostic utility of the diverse molecular data among IncRNA, DNA Methylation, microRNA, and mRNA across five human cancers. PLoS One. 2015;10(11):e0142433.

7. Abrahamsson A, Dabrosin C. Tissue specific expression of extracellular microRNA in human breast cancers and normal human breast tissue in vivo. Oncotarget. 2015;6(26):22959-69.

8. Liu HT, Xing AY, Chen X, Ma RR, Wang YW, Shi DB, Zhang H, Li P, Chen HF, Li YH, et al. MicroRNA-27b, microRNA-101 and microRNA-128 inhibit angiogenesis by down-regulating vascular endothelial growth factor $C$ expression in gastric cancers. Oncotarget. 2015;6(35):37458-70.

9. Macfarlane LA, Murphy PR. MicroRNA: biogenesis, function and role in cancer. Curr Genomics. 2010;11(7):537-61.

10. Garzon R, Fabbri M, Cimmino A, Calin GA, Croce CM. MicroRNA expression and function in cancer. Trends Mol Med. 2006;12(12):580-7.

11. Shenouda SK, Alahari SK. MicroRNA function in cancer: oncogene or a tumor suppressor? Cancer Metastasis Rev. 2009;28(3-4):369-78.
12. Han G, Wang Y, Bi W, Jia J, Wang W. MicroRNA-124 functions as a tumor suppressor and indicates prognosis in human osteosarcoma. Experimental and therapeutic medicine. 2015;9(3):679-84.

13. Azam AT, Bahador R, Hesarikia H, Shakeri M, Yeganeh A. Downregulation of microRNA-217 and microRNA-646 acts as potential predictor biomarkers in progression, metastasis, and unfavorable prognosis of human osteosarcoma. Tumour Biol. 2015

14. Wang T, Ji F, Dai Z, Xie Y, Yuan D. Increased expression of microR $N A-191$ as a potential serum biomarker for diagnosis and prognosis in osteosarcoma. Cancer Biomark. 2015;15(5):543-50.

15. Yang Z, Zhang Y, Zhang X, Zhang M, Liu H, Zhang S, Qi B, Sun X. Serum microRNA-221 functions as a potential diagnostic and prognostic marker for patients with osteosarcoma. Biomed Pharmacother. 2015,75:153-8.

16. Zhou $\mathrm{H}$, Zhang $M$, Yuan $\mathrm{H}$, Zheng W, Meng C, Zhao D.MicroRNA-154 functions as a tumor suppressor in osteosarcoma by targeting Wnt5a. Oncol Rep. 2015.

17. Xu R, Liu S, Chen H, Lao L. MicroRNA-30a downregulation contributes to chemoresistance of osteosarcoma cells through activating Beclin-1mediated autophagy. Oncol Rep. 2015.

18. Ling H, Pickard K, Ivan C, Isella C, Ikuo M, Mitter R, Spizzo R, Bullock MD, Braicu C, Pileczki V, et al. The clinical and biologícal significance of MIR-224 expression in colorectal cancer metastasis. Qut. 2015

19. Wan Y, Zeng ZC, Xi M, Wan S, Hua W, Liel YL, Zhou YL, Luo HW, Jiang FN, Zhong WD. Dysregulated microRNA-224/apelin axis associated with aggressive progression and poor prognosis in patients with prostate cancer. Hum Pathol. 2015;46(2):295-303.

20. Liu H, Li P, Li B, Sun P, Zhang J, Wang B, Jia B. RKIP suppresses gastric cancer cell proliferation and invasion and enhances apoptosis regulated by microRNA-224. Tumour biology : the journal of the International Society for Oncodevelopmental Biology and Medicine. 2014;35(10):10095-103.

21. Liu L, Chen K, Wu J, Shi L, Hu B, Cheng S, Li M, Song L. Downregulation of miR-452 promotes stem-like traits and tumorigenicity of gliomas. Clin Cancer Res. 2013;19(13):3429-38.

He Z, Xia Y, Pan C, Ma T, Liu B, Wang J, Chen L, Chen Y. Up-regulation of R-452 inhibits metastasis of non-small cell lung cancer by regulating BMI1. Cell Physiol Biochem. 2015;37(1):387-98.

Puerta-Gil P, Garcia-Baquero R, Jia AY, Ocana S, Alvarez-Mugica M, AlvarezOssorio JL, Cordon-Cardo C, Cava F, Sanchez-Carbayo M. miR-143, miR-222, and miR-452 are useful as tumor stratification and noninvasive diagnostic biomarkers for bladder cancer. Am J Pathol. 2012;180(5):1808-15.

24. Kristensen H, Haldrup C, Strand S, Mundbjerg K, Mortensen MM, Thorsen K, Ostenfeld MS, Wild PJ, Arsov C, Goering W, et al. Hypermethylation of the GABRE miR-452 miR-224 promoter in prostate cancer predicts biochemical recurrence after radical prostatectomy. Clin Cancer Res. 2014;20(8):2169-81.

25. Veerla S, Lindgren D, Kvist A, Frigyesi A, Staaf J, Persson H, Liedberg F, Chebil G, Gudjonsson S, Borg A, et al. MiRNA expression in urothelial carcinomas: important roles of miR-10a, miR-222, miR-125b, miR-7 and miR-452 for tumor stage and metastasis, and frequent homozygous losses of miR-31. International journal of cancer Journal international du cancer. 2009;124(9):2236-42.

26. Zheng Q, Sheng Q, Jiang C, Shu J, Chen J, Nie Z, Lv Z, Zhang Y. MicroRNA-452 promotes tumorigenesis in hepatocellular carcinoma by targeting cyclindependent kinase inhibitor 1B. Mol Cell Biochem. 2014;389(1-2):187-95.

27. Enneking WF, Spanier SS, Goodman MA. A system for the surgical staging of musculoskeletal sarcoma. Clin Orthop Relat Res. 1980;153:106-20.

28. Zhang Y, Han L, Pang J, Wang Y, Feng F, Jiang Q. Expression of microRNA-452 via adenoviral vector inhibits non-small cell lung cancer cells proliferation and metastasis. Tumour Biol. 2015.

29. Hu Q, Gong JP, Li J, Zhong SL, Chen WX, Zhang JY, Ma TF, Ji H, Lv MM, Zhao $J H$, et al. Down-regulation of miRNA-452 is associated with adriamycinresistance in breast cancer cells. Asian Pac J Cancer Prev. 2014;15(13):5137-42.

30. Fabian MR, Sonenberg N, Filipowicz W. Regulation of mRNA translation and stability by microRNAs. Annu Rev Biochem. 2010;79:351-79.

31. Ventura A, Jacks T. MicroRNAs and cancer: short RNAs go a long way. Cell. 2009;136(4):586-91.

32. Hashimoto Y, Akiyama Y, Yuasa Y. Multiple-to-multiple relationships between microRNAs and target genes in gastric cancer. PLoS One. 2013;8(5), e62589.

33. Koren A, Rijavec M, Kern I, Sodja E, Korosec P, Cufer T. BMI1, ALDH1A1, and CD133 transcripts connect epithelial-mesenchymal transition to cancer stem cells in lung carcinoma. Stem Cells Int. 2016;2016:9714315.

34. Yuan B, Zhao H, Xue X, Zhou J, Wang X, Han Y, Zhang L, Guo X, Zhi Q. Prognostic value and clinicopathological differences of bmi1 in gastric cancer: a meta-analysis. Anticancer Agents Med Chem. 2016;16(4):407-13. 
35. Luo HB, Li B, Yuan WG, Xu CR. Knockdown of Bmi1 inhibits bladder cancer cell growth both in vitro and in vivo by blocking cell cycle at G1 phase and inducing apoptosis. J Huazhong Univ Sci Technolog Med Sci. 2015;35(5):730-5.

36. Siddique HR, Saleem M. Role of BMI1, a stem cell factor, in cancer recurrence and chemoresistance: preclinical and clinical evidences. Stem Cells. 2012;30(3):372-8.

37. Wu Z, Min L, Chen D, Hao D, Duan Y, Qiu G, Wang Y. Overexpression of BMI-1 promotes cell growth and resistance to cisplatin treatment in osteosarcoma. PLoS One. 2011;6(2), e14648.

38. Brennecke J, Stark A, Russell RB, Cohen SM. Principles of microRNA-target recognition. PLoS Biol. 2005;3(3), e85.

39. Krek A, Grun D, Poy MN, Wolf R, Rosenberg L, Epstein EJ, MacMenamin P, da Piedade I, Gunsalus KC, Stoffel M, et al. Combinatorial microRNA target predictions. Nat Genet. 2005;37(5):495-500.

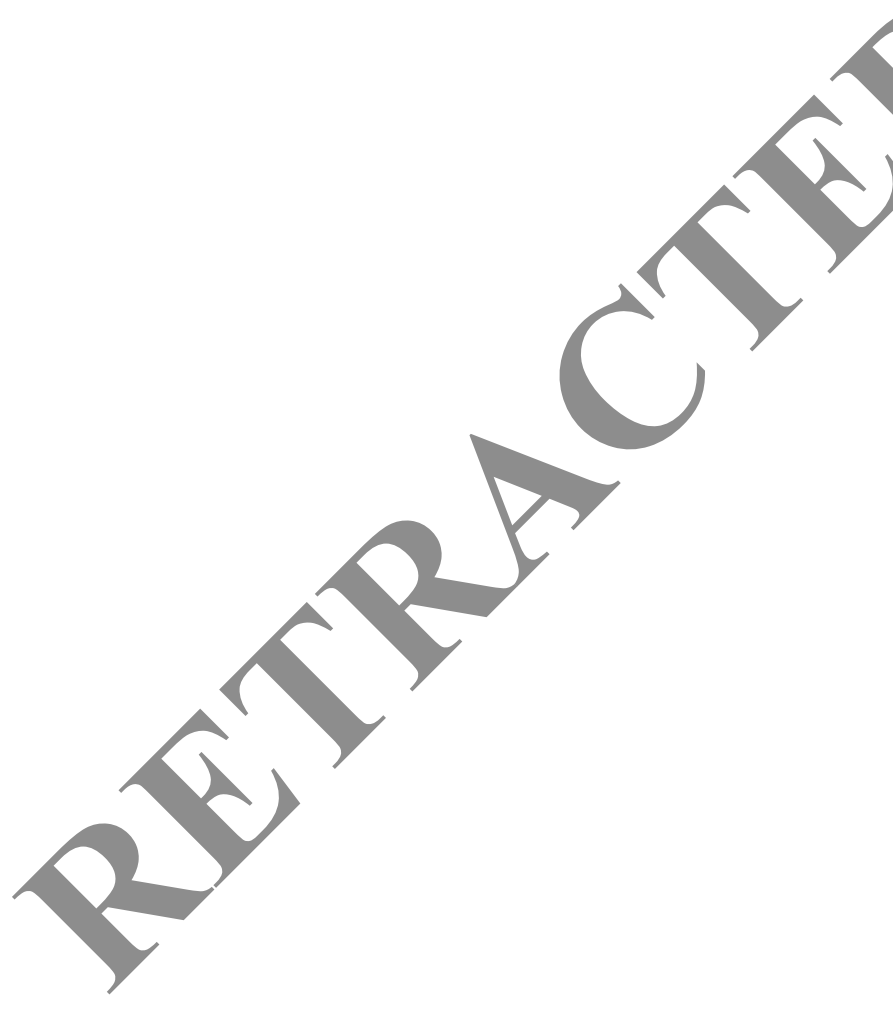

Submit your next manuscript to BioMed Central and we will help you at every step:

- We accept pre-submission inquiries

- Our selector tool helps you to find the most relevant journal

- We provide round the clock customer support

- Convenient online submission

- Thorough peer review

- Inclusion in PubMed and all major indexing services

- Maximum visibility for your research

Submit your manuscript at www.biomedcentral.com/submit 